\title{
Herencias moderno-coloniales en actuales discursos sobre la Orinoquia colombiana
}

Armando Durán. Universidad del Rosario, Bogotá, Colombia.

RESUMEN | En la actualidad existen tres tipos de discursos que están construyendo el presente y futuro de la región orinocense de Colombia: como un espacio inmenso y vacío (discurso hegemónico), como un área para la conservación y como un lugar intercultural. Se defiende la tesis de que estos discursos contemporáneos sobre y desde la Orinoquia colombiana contienen herencias moderno-coloniales, esto es, exhiben relaciones múltiples de dominación, que se han sedimentado y transformado en el tiempo. Metodológicamente, para la identificación de los discursos se priorizó una perspectiva cualitativa; en particular, se realizó un análisis del discurso en documentos históricos, y también en textos contemporáneos existentes y en otros producidos a partir de entrevistas y foros departamentales. Se destaca el reto social de agenciar dispositivos de relación plural que coadyuven a visibilizar y a reconocer, como legítimos, conocimientos, subjetividades y dominios que vienen siendo, según los casos, negados, violentados o subsumidos desde lógicas hegemónicas de sentido.

PALABRAS CLAVE | Historia regional, desarrollo territorial, desarrollo sustentable.

ABSTRACT | Three representational discourses about Orinoquia region of Colombia and are shaping the present and future of this area. The first views it as an immense and empty space hegemonic discourse -; the second, as an area for conservation; and the third, as an intercultural place. We defend the thesis that these contemporary perspectives about the Colombian Orinoquia have a modern-colonial heritage, that is to say, they are structured by multiple relations of domination, which have been settled and transformed in time. Methodologically, this paper prioritizes a qualitative standpoint for the identification of the discourses; through an analysis of historical and contemporary documents, and of interviews and departmental forums. It highlights the social challenge of promoting means for plural relations that might help make visible and recognize as legitimate, the knowledge, subjectivities and dominions which have been, in many cases, denied, violated or subsumed by hegemonic logics of significance.

KEY WORDS | Regional history, territorial development, sustainable development.

Recibido el 14 de diciembre de 2010, aprobado el 24 de septiembre de 2011

E-mail: barichara72@hotmail.com

Este artículo se basa en la investigación "La mejor Orinoquia que podemos construir", realizada en la Universidad de los Andes, en el año 2009; y en el proceso investigativo que siguió en el 2010, en el marco del Programa de Gestión y Desarrollo Urbanos-Ekística, de la Facultad de Ciencia Política y Gobierno y la Facultad de Relaciones Internacionales, Universidad del Rosario, Bogotá, Colombia. 


\section{Introducción}

Los discursos dominantes que en la actualidad construyen la Orinoquia colombiana evidencian procesos de sedimentación histórica colonial, esto es, configuran modos particulares de comprensión de este territorio y de sus pobladores desde un intento por reeditar e imponer las teorías del progreso y del desarrollismo en la región. Tales formas de ver esta realidad social, antes de ser neutrales, condicionan la memoria e historicidad a partir de marcos epistémicos y tecnológicos eurocéntricos (Dussel, 2007), basados en la promesa de la prosperidad y la felicidad para todos en el futuro más inmediato de la Orinoquia.

El discurso hegemónico ${ }^{1}$ contemporáneo de la cuenca del Orinoco se asemeja a un gran lienzo en blanco, dispuesto y ávido de la intervención e inventiva del capital transnacional. Este discurso dominante opera dentro de una lógica de poder (Quijano, 2001) de saber (Mignolo, 2003) y de ser (Maldonado-Torres, 2007) que se podría definir como colonialidad de la naturaleza (Lander, 2000; Escobar, 2000, 2003). El discurso dominante sobre y desde la Orinoquia caracteriza a esta región como una zona con territorios inmensos y vacios, que otorgan la oportunidad para alcanzar el desarrollo económico y social que la región necesita. Los principales actores que sustentan este discurso son el gobierno nacional (saliente) y gremios productivos (de palmeros, arroceros, ganaderos, petroleros). De ese modo, la Orinoquia colombiana se asume como una tierra de promisión que es necesario explotar y conquistar, debido a los atributos de riqueza ecosistémica que le son característicos; como un espacio vacío sin mayores obstáculos ambientales y culturales que vencer, y como una tierra llena de oportunidades para los actores sociales dispuestos a competir en el mercado mundial.

Sin embargo, coexisten con la anterior otras formas de enunciación que trazan otras visiones y traducen otras prácticas que se anudan, visibilizando y recuperando otros sistemas de conocimiento, otras subjetividades y dominios, tanto en la biodiversidad como en relaciones interculturales. Es así que otro discurso irrumpe, que lucha por ser visible y reconocido como legítimo: es el que define la región como área para la conservación de las especies de flora y fauna presentes en la cuenca, especialmente por poseer alta diversidad biológica y, al mismo tiempo, por encontrarse en situación de alta fragilidad ecosistémica. Los voceros principales de esta percepción son organizaciones no gubernamentales del orden nacional e internacional interesadas en la defensa del medio natural. Un tercer discurso, y que no es hegemónico, concibe esta región como un lugar intercultural, donde se mezclan distintas culturas dentro de relaciones desiguales de poder y de saber. Esta visión es respaldada por pobladores locales tradicionales y por instituciones descentralizadas de carácter gubernamental. Además, por algunos sectores de la academia regional y nacional.

1 Lo hegemónico entendido como relación de poder, de dominación, al punto de que "hace que las personas actúen como si ello fuera natural, normal o simplemente existiese consenso" (Van Dijk, 2000, p. 43). Sin embargo, este control no es total, debido que las experiencias y conocimientos de vida de las personas no son reductibles a una unidad o esencia de lo social. 
El artículo argumenta la siguiente tesis central: los discursos contemporáneos que construyen la cuenca del Orinoco expresan el devenir del síndrome de la colonialidad, esto es, exhiben relaciones múltiples de dominación, que se han sedimentado y transformado históricamente. Por "discurso" se comprende el conjunto de percepciones y conocimientos que los diferentes actores sociales expresan y defienden sobre un hecho o realidad social. Los actores (personas; grupos económicos nacionales y transnacionales; partidos políticos; cooperativas de trabajadores; organizaciones ambientales; grupos étnicos; sectores académicos, sociales y eclesiásticos; gobiernos locales, departamentales y nacionales, etcétera) en su cotidianidad originan y legitiman sentidos y valores con respecto de la vida social. Estos pueden ser identificados y analizados a partir de las opiniones expresadas de manera individual o desde las creencias que se van gestando al colectivizarse particulares tipos de conocimiento sobre un acontecimiento cotidiano. Dicho de otra manera, además de la cognición individual, el discurso implica esencialmente una cognición sociocultural. Ello porque los sujetos sociales comparten con otros miembros de su grupo, comunidad o cultura, normas, valores, creencias, reglas de comunicación y representaciones sociales que se expresan en prácticas, intereses y orientaciones de la vida personal y social (Van Dijk, 2000).

En cuanto a lo metodológico, para la identificación de los discursos se priorizó una perspectiva cualitativa; específicamente se utilizó el análisis del discurso para estudiar documentos históricos que han dado cuenta de la región, y textos primarios (entrevistas y foros departamentales) y secundarios que representan "voces" más contemporáneas de la cuenca, en particular de dirigentes gremiales y de sectores estatales, sociales y académicos. Se adoptó un enfoque del análisis del discurso que hace énfasis en el nivel de sentido macro, esto es, un análisis del discurso que busca privilegiar los sentidos "globales" que expresan los textos, más que un análisis que se detiene en cada uno de los elementos (palabras) que componen tales significaciones (Van Dijk, 2000).

Para dar cuenta de lo planteado, el escrito se estructura en tres partes. En la primera se describe en qué consiste el síndrome de la colonialidad en la Orinoquia colombiana. En el segundo apartado, se exponen tres tipos de discursos contemporáneos que están construyendo el presente y futuro de la cuenca del Orinoco. Por último, se destaca el reto social de agenciar ${ }^{2}$ dispositivos de relación plural que coadyuven a visibilizar y a reconocer, como legítimos, conocimientos, subjetividades y dominios que vienen siendo, según los casos, negados, violentados o subsumidos desde lógicas hegemónicas de sentido.

\section{El síndrome de la colonialidad en la Orinoquia colombiana}

A finales del siglo XV y principios del XVI, emergen las condiciones que hacen posible lo que se ha llamado una economía-mundo, discontinuidad histórica que correlaciona el proceso de intrusión y de dominación de América, con la formación del mercado liberal que tuvo como centro Europa Occidental (Wallerstein, 1984;

2 Se comprende la "agencia" como la capacidad de hacer cosas, más que la intención del individuo de llevarlas a cabo. Véase Giddens (1995). 
Dussel, 1995). Tales acontecimientos introducen en los territorios conquistados el sindrome de la colonialidad: explotación económica, sujeción política y eliminación cultural. Siguiendo a Enrique Dussel, la "aparición" del "otro", como un fantasma - del indígena que Colón vio sobre las playas en octubre de 1492 - fue prontamente "encubierta" bajo la máscara de los "otros" que los europeos portaban en su imaginario. "En realidad no 'vieron' al indio: imaginaron los Otros que portaban en sus recuerdos de europeos. Ese indio fue visto como la alteridad europea, como el 'infiel' que durante mil años había luchado contra el cristiano en el Mediterráneo. Por ello fue violentamente atacado, desarmado, servilmente dominado y rápidamente diezmado" (Dussel, 2007, p. 194). Se construye así un síndrome de la colonialidad, ${ }^{3}$ que en los últimos tiempos instaura formas de ser (Mignolo, 2003), de saber (Lander, 2000) y de poder (Quijano, 2001) revestidas del atributo de la cultura panóptica: ${ }^{4}$ un triedro de fuerzas de dominación que pretenden tener la facultad de agenciar una realidad social, con la particularidad de que toda ella puede ser escrutada, controlada desde un punto cero, ${ }^{5}$ desde una mirada inobservada.

La colonialidad del poder refiere a la clasificación e identificación social por medio del patrón de una "raza superior"': la blanca o europea, que condujo al despojo, la represión y la servidumbre de las identidades aborígenes colonizadas (mayas, aztecas, incas, aymaras, muiscas, etcétera) (Quijano., 2001). La colonialidad del saber irrumpe cuando la cultura colonizadora instaura el predominio de formas de conocer y de producir conocimiento orientadas por la fe y, luego, por la racionalidad liberal. Así, de manera inmediata, las otras formas de saber son trasformadas no solo en diferentes, sino en carentes, en arcaicas, primitivas, tradicionales, premodernas (Lander, 2000). La colonialidad del saber y del poder engendran la colonialidad del ser (Mignolo, 2003), que se funda en la deshumanización de los sujetos colonizados, esto es, en su negación ontológica (Maldonado-Torres, 2007).

Este síndrome de colonialidad, que avanza mutando hasta el presente, se evidencia en el caso de la Orinoquia colombiana de múltiples maneras. En el caso del presente escrito, se describe cómo han operado estos dispositivos de dominación en discursos que definen hoy esta región. Se asume que estos discursos, más que traducir sentidos y dominios sobre determinada realidad social, lo que auspician es la creación de significaciones que confieren, en algunos casos, el estatus de realidad social (Foucault, [1970] 2002).

Veamos a continuación cómo se expresan estas formas de sujeción social, económica, política y cultural, en los discursos del "ser salvaje" y de la "pureza de sangre" en los siglos XV-XVI y en el siglo XIX, respectivamente.

3 Colonialidad es distinto a colonialismo. El colonialismo denota una relación política y económica, en la cual la soberanía de un pueblo reside en el poder de otro pueblo o nación. La colonialidad refiere a un patrón de poder que emergió como resultado del colonialismo moderno. Da cuenta de la forma cómo el trabajo, el conocimiento, la autoridad y las relaciones intersubjetivas se articulan entre sí, mediante del mercado capitalista mundial y la idea de raza. Así, aunque el colonialismo precede a la colonialidad, la colonialidad sobrevive al colonialismo (Maldonado-Torres, 2007).

4 La cultura panóptica, imaginario de vida que aspira a tener la capacidad de adoptar una visión soberana sobre el mundo; en especial, su potencia emerge del hecho de adjudicarse la imposibilidad de su percepción, de su representación.

5 El trabajo de Santiago Castro (2005) ejemplifica cómo ese imaginario del "punto cero" fue característico de la ciencia ilustrada europea.

6 Tal grado de superioridad se adjudicaba según los grados de humanidad atribuidos a las identidades en cuestión. En términos generales, entre más clara la piel del sujeto, más cerca estará de representar el ideal de una humanidad completa (Maldonado-Torres, 2007). 


\section{Los discursos del "ser salvaje" y de la "pureza de sangre"}

La Orinoquia colombiana se ha construido desde distintos discursos, como el descrito por el misionero jesuita José Gumilla [1741] (1944), que fundaba este territorio como un espacio "triste", albergue de "naciones desnudas" y de "bocas de los dragones". Son discursos contenidos en las experiencias de los primeros europeos que desembarcaron en el delta del río Orinoco y que, según el autor, relatan "el mal pasaje que le dieron, y dan todavía a los navegantes" (Gumilla, 1944, p. 58). José Gumilla hace referencia particularmente a la travesía realizada por Cristóbal Colón al intentar ingresar a esta cuenca oriental desde las islas Margarita en el año de 1498, y a la experiencia de Diego de Ordaz que, según este misionero, fue el primer español que navegó el río Orinoco, año de 1535.

Estas "primeras" percepciones de la cuenca del Orinoco configuran estos territorios desde la imagen de la violencia constitutiva (Serje, 2005) — vale decir, desde el discurso del ser salvaje-, como periferias de la civilización que por su "desnudez" evidencian los gritos de la inmadurez, del salvajismo y la anarquía. Los habitantes de tales "raudales peligrosos del río Orinoco" se asemejan a las "arañas venenosas", a las "hormigas venenosas de extraña figura", al "pescado de puya venenosa", a "los mosquitos que dejan un gusano cruel", o al "curare, veneno fatal".

El informe sobre la provincia de Casanare de la Comisión Corográfica [1856] (1959) describe que "dos grandes obstáculos se oponen en esa provincia a su desarrollo, que son: el clima y los indios. Ambos pueden con el tiempo modificarse, pero, entre tanto, será útil examinarlos para ver si desde ahora se puede hacer algo para acelerar esa modificación" (Comisión Corográfica, 1956, p. 376). Este documento ilustra el discurso de pureza de sangre, que era el eje alrededor del cual se construía la subjetividad de los actores sociales de la Nueva Granada. "Ser blancos no tenía que ver tanto con el color de la piel como con la escenificación de un imaginario cultural tejido por creencias religiosas, tipos de vestimenta, certificados de nobleza, modos de comportamiento, y con formas de producir conocimientos" (Castro-Gómez, 2005, p. 68). De acuerdo con el autor, el discurso ilustrado neogranadino - es decir, las formas de conocimiento resultado de la nueva ciencia- no solo planteaba la superioridad de unos hombres sobre otros, sino también la superioridad de unas formas de conocimiento sobre otras. El discurso de la geografía, la comprensión de los climas y las particularidades de su vida vegetal y animal, que correspondía al control territorial en la Nueva Granada, respondía no solo a los imperativos geopolíticos del Estado borbón, sino también al intento de las elites criollas por imponer su hegemonía sobre las diversas poblaciones que habitaban ese territorio (Castro-Gómez, 2005).

En este contexto es pertinente preguntarse por el devenir, en la actualidad, del síndrome de la colonialidad; esto es, por las formas de dominación que persisten en unificar, desde una visión de la vida social que pretende ser universal, los múltiples modos en que los grupos humanos expresan sus formas de ser, hacer, tener y estar. Este interrogante puede ser expresado como sigue: ¿̇e qué manera el síndrome de la colonialidad se relaciona con los discursos contemporáneos que construyen la Orinoquia colombiana? 


\section{Discursos contemporáneos de la cuenca del Orinoco}

En la cuenca del Orinoco concurren las aguas tributarias que confluyen en el gran río Orinoco entre los países de Colombia y Venezuela. Su extensión es de $991.587 \mathrm{~km}^{2}$, que equivale al 0,06 por ciento de la superficie mundial; cerca de $644.423 \mathrm{~km}^{2}(65$ por ciento de la cuenca) se localizan en Venezuela, representando el 70,6 por ciento de esa nación (Romero, Galindo, Otero \& Armenteras, 2004). El 35 por ciento restante se encuentra en territorio de Colombia, cerca de $347.164 \mathrm{~km}^{2}$, y abarca 30,4 por ciento del territorio continental del país. Incluye la totalidad de los departamentos del Vichada $\left(100.242 \mathrm{~km}^{2}\right)$, Arauca $\left(23.818 \mathrm{~km}^{2}\right)$ y Casanare $\left(444.640 \mathrm{~km}^{2}\right)$, así como el 95 por ciento del Meta $\left(81.741 \mathrm{~km}^{2}\right)$ y, en menor proporción, parte de Bogotá y de los departamentos de Caquetá, Cundinamarca, Guainía, Guaviare, Huila, Norte de Santander, Santander y Vaupés (Rodríguez, 2009).

\section{MAPA 1 | Orinoquia colombiana}

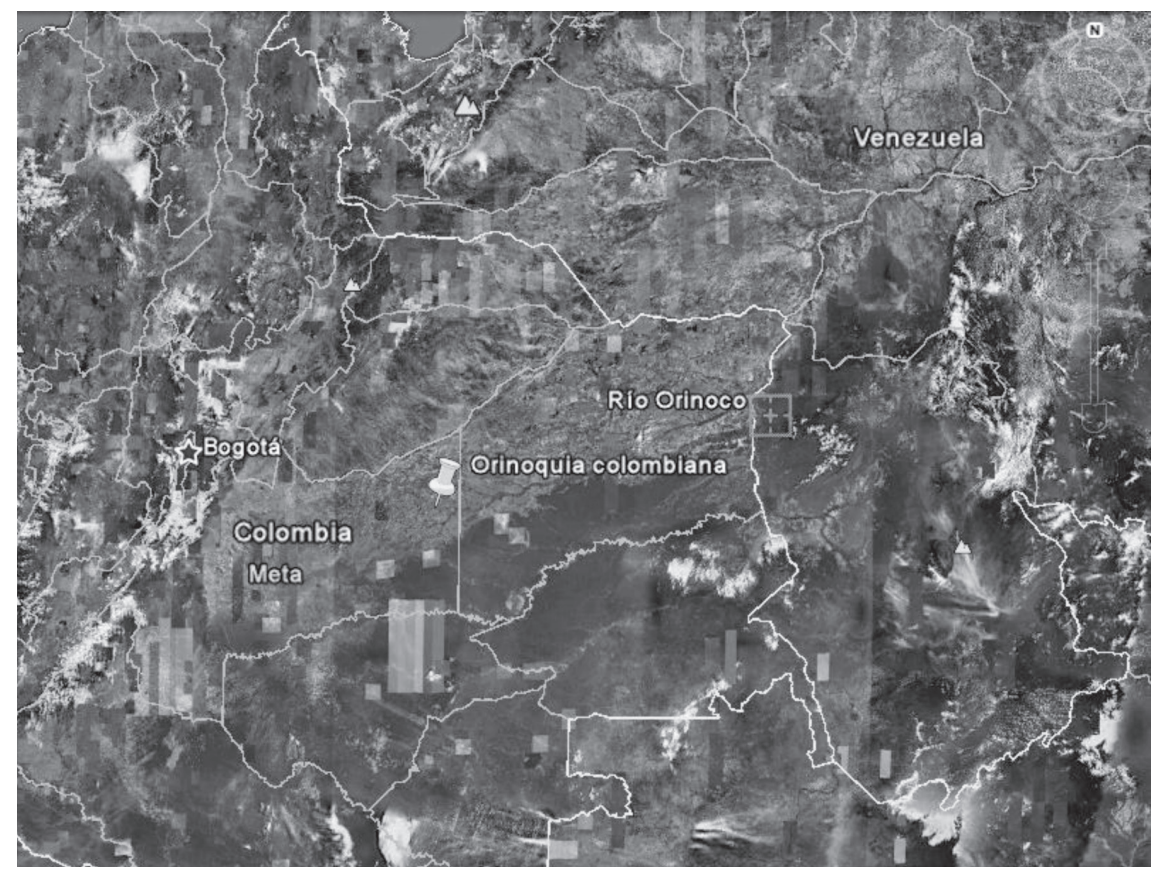

Fuente Google EARTh, 2011.

Contemporáneamente, la región del Orinoco colombiano se ve configurada por tres grandes discursos: de territorio salvaje a "tabula rasa" (actualmente el hegemónico); de tierras "inundables" a la romantización de su carácter silvestre; de espacio 
social a lugar intercultural. Estos discursos implican no solo imágenes de realidad desde y sobre este territorio, sino fundamentalmente relaciones y prácticas que allí se hacen posibles. Tales significaciones se fundan en una tradición de sentido en que se lee no solamente la realidad de estos espacios, de estos lugares y de sus gentes, sino la de la sociedad que los imagina (Serje, 2005).

\section{De territorio salvaje a "tabula rasa"}

¿Será que quedaron "atrás" esas percepciones dominantes que describían la región del Orinoco como sitio aislado y poblado de indios "salvajes", "bárbaros", "pobres" e "ignorantes"? "Ya dije arriba el modo bárbaro, cruel y necio, con que los indios, en su ciega gentilidad, curaban (...). Ahora será muy del caso (porque este libro también se ordena al bien de aquellas pobres gentes) apuntar brevemente los remedios usuales, que los padres misioneros tienen prontos, y llevan en sus espirituales correrías, para bien de aquellos pobres ignorantes" (Gumilla, 1944, p. 156). Los discursos que se agencian en el presente histórico emergen sobre las huellas de aquellos otros discursos que comúnmente eran manifiestos en los relatos de misioneros y cronistas de tiempos pasados; esto es, los discursos que actualizan la Orinoquia se constituyen como palimpsestos de los predecesores.

En la actualidad existe un discurso dominante que define la región del Orinoco como territorio en formación. En el Plan de Desarrollo Nacional 2006-2010, El Estado comunitario: desarrollo para todos, se clasificó el país por grupos de regiones, teniendo en cuenta la visión estratégica de desarrollo, el desempeño económico y las capacidades endógenas (Departamento Nacional de Planeación [DNP], 2007). Estos criterios han modelado la percepción que el gobierno nacional tiene sobre los diferentes territorios del país. Según esa clasificación, la Orinoquia se encuentra en fase de formación: es un territorio dispuesto a ser desarrollado, visión que deviene en imágenes y realidades que respaldan y consolidan esta zona de Colombia como un territorio abierto a la exploración y abierto a nuevas colonizaciones. La Agencia Nacional de Hidrocarburos (ANH), que es el administrador integral de los recursos hidrocarburíferos de propiedad de la Nación, al respecto afirma:

En la actualidad toda la región de la Orinoquia se encuentra en desarrollo del proyecto consecución de información-TEA. Se han conformado ocho bloques para el estudio de la región, con el objetivo de conocer la geología de la cuenca de los llanos Orientales y así identificar las zonas donde es probable la existencia de crudos pesados. Este proyecto tiene una duración mínima de tres años, extensible a criterio técnico de la ANH de acuerdo con el desarrollo del mismo (ANH, 2009, p. 2).

Se trata de un sitio lleno de posibilidades y oportunidades, para la agroindustria principalmente. Hoy, en el departamento del Meta se están desarrollando tres grandes proyectos de producción de agrocombustibles: i) Aceites Manuelita, en San Carlos de Guaroa. Esta planta tiene la capacidad de producir 100.000 toneladas de biodiesel al año; ii) Biocastilla, en Castilla La Nueva. Se propone sembrar 7.700 
hectáreas de palma, procesar 35.000 toneladas de aceite y generar 2.200 empleos directos; iii) Bio-D, proyecto en el cual están asociados dieciocho palmicultores del Meta. Tienen la planta en Facatativá, con capacidad para producir 100.000 toneladas de biodiesel (Viloria, 2009).

Este discurso, que presenta la región como territorio en formación, abre escenarios de optimismo para el gobierno nacional, debido al carácter pretendidamente natural que lo dispone como tabula rasa solo a la espera de la iniciativa productiva nacional y transnacional; y, en especial, porque - a diferencia de otras regiones del país (región del Amazonas) — la iniciativa productiva no tendría mayor "obstáculo ecológico". Lo anterior, entre otras cosas, al adjudicar exclusivamente a los morichales un valor ambiental, desestimando el valor de otros ecosistemas naturales, como las sabanas tropicales, el complejo de humedales (compuestos por esteros, chucuas, lagunas, madreviejas, tembladales, zurales), las selvas y montañas húmedas, y los ríos. El conjunto alberga un mosaico con 156 tipos de ecosistemas (Romero et al., 2004), de los cuales 92 corresponden a ecosistemas de tipo natural. Como se describe más adelante, la región tiene una de las mayores riquezas de especies de peces de agua dulce del mundo, una de las mayores en diversidad de aves, y se destaca por su muy alta diversidad de gramíneas tropicales (Rodríguez, 2009).

El discurso que connota la región como territorio en formación trae consigo, entre otras cuestiones, no solo la invisibilización de la diversidad biológica, sino la de las historias y culturas presentes en él. Tal es la visión que se expresa en el discurso del ex presidente Álvaro Uribe:

Pero, miren: le veo a esa Orinoquía [sic] un futuro ya inmediato en el agro. En esos 600.000 kilómetros diríamos que hay 350.000 de selva y 250.000 de sabanas. ¿Ustedes saben lo importante que es para el mundo agropecuario tener allí 250.000 kilómetros planos, sin piedra, listicos para cultivar y sin el obstáculo ecológico de que hay que llegar con el hacha? Y, además, ustedes han tenido muy buen sentido, que es cuidar esos morichales, esos oasis. Yo veo hoy un volcamiento muy importante de los colombianos a colonizar agricultura allá (Uribe, 2003, p. 2; destacados nuestros).

$\mathrm{Y}$ es que este discurso sobre el territorio orinocense ha configurado prácticas estatales y privadas que forjan realidad. Siguiendo a Viloria (2009), la Ley 939, de 2004, y su decreto 1970, de 2005, reglamentan la exención de renta para nuevos cultivos de tardío rendimiento en palma de aceite, caucho, cacao, cítricos y frutales. Los beneficios cobijan a los nuevos cultivos por diez años, a partir del momento en que inician la producción. Por su parte, en su gran mayoría estos beneficios han sido recibidos por un grupo reducido de cultivadores, y a ellos no tienen acceso los campesinos pobres: "De los recursos de Agro Ingreso Seguro, más del 95 por ciento de lo entregado ha sido para los grandes y medianos empresarios" (López Montaño, 2008, p. 29, en Viloria, 2009). Además, comenta Viloria, los subsidios del gobierno nacional a los proyectos de siembra de palma de aceite y fabricación de biodiesel y etanol han sido decisivos para la consolidación de los mismos. De igual 
forma ocurre con la adecuación de las tierras: la mayoría de los suelos de la Orinoquia tienen problemas de acidez, exceso de aluminio y óxido de hierro, factores tóxicos para una parte de la vegetación de la zona. Este problema obliga a que los agricultores corrijan las deficiencias del suelo con enmiendas físicas y químicas que permiten fijar el aluminio intercambiable y así hacer más productivos los terrenos. El gobierno nacional apoya estos proyectos de corrección física y química de los terrenos mediante el Incentivo de Capitalización Rural que otorga el Fondo para el Financiamiento del Sector Agropecuario (Finagro) (Viloria, 2009).

El siguiente relato del Grupo Empresarial Manuelita describe el inicio de un macroproyecto para el cultivo de la palma de aceite en el Casanare.

Se compraron 25.000 hectáreas, que en la mayoría eran fincas ganaderas con hatos entre 10.000 y 30.000 cabezas de ganado, tierras con títulos y tradición. Además se adquirieron algunas Unidades Agrícolas Familiares mediante sociedades. La zona tiene disponibilidad de 300.000 hectáreas aptas para cultivos como palma, forestas y caucho. Se contrató una firma para que haga el plan maestro de manejo del suelo; esta investigación reúne estudios biológicos, geológicos y de infraestructura necesarios para la operación, tuvo un valor cercano a los 1.500 millones de pesos. Lo más probable es que se tenga que hacer un distrito del riego de mayor dimensión al construido en el Meta (Giovanelli, 2009, p. 4).

Inquieta el hecho de que mientras el Plan de Desarrollo Nacional 2006-2010 le otorga un papel muy claro al sector privado en el desarrollo de la Orinoquia, no les asigna un papel explícito a actores de la región, como son las comunidades indígenas y campesinas, ni al sector privado tradicional de la zona. Esa orientación desconoce uno de los principios básicos de cualquier propuesta de política pública, como es la agencia del bien común. La pregunta que inmediatamente se suscita es: ¿̇cómo procurar que los diferentes actores del orden local, regional y nacional confluyan en fomentar y consolidar propuestas de desarrollo desde y para la región, enraizadas en el bien común?

Este discurso, que configura la Orinoquia como una gran extensión de territorios vacíos, despoblados, un gran lienzo en blanco ávido de un "artista creador", reedita "el vacío originario" con que interpretaron los conquistadores este continente, ya hace cinco siglos. Esta reedición se actualiza con el discurso del desarrollismo (Escobar, 1998), caracterizado por el ideal del progreso (Bury, 1971). Tal imaginario emerge sobre y desde la región como un horizonte de sentido dominante que fija que todas las sociedades han de transitar por estadios sucesivos de evolución (Comte, 1984) y crecimiento (Rostow, 1960), hasta que puedan alcanzar el tan anhelado "desarrollo" individual y colectivo. Los distintos estilos de vida pretenden ser conducidos por este patrón universal de mejoramiento continuo, un esfuerzo por centralizar el conocimiento de la naturaleza y sus relaciones desde una mirada colonizadora, expropiando cognitiva y culturalmente a los pobladores que habitan estos territorios. 


\section{De tierras “inundables” a la romantización de su carácter silvestre}

Un correlato de la imagen de la tabula rasa presenta la región orinocense desde sus cualidades biofísicas: bioma de sabana y sistemas ecológicos de las montañas tropicales húmedas (Rodríguez, 2009). Tradicionalmente, cuando se hace referencia a la Orinoquia colombiana se la asimila a los "llanos orientales", que evocan un espacio plano y uniforme, especial para la cría de bovinos. Desde esta visión del sentido común urbano, las sabanas de los departamentos de Arauca y Casanare se conocen como "inundables", como tierras que carecen de diversidad biológica. ${ }^{7}$

Contemporáneamente han emergido discursos impulsados por organizaciones internacionales como World Wide Fund for Nature (WWF, Fondo Mundial para la Naturaleza), y por organizaciones nacionales como el Instituto de Investigación de Recursos Biológicos Alexander von Humboldt (IAvH), entre otras, que vienen cuestionando tales visiones de la región. Se argumenta que estas sabanas, más que presentar "fallas" naturales, son en realidad ecosistemas complejos denominados humedales, los cuales son vitales en la regulación del ciclo del agua de la cuenca. Se estima que la diversidad de plantas en la zona plana es muy alta, con un total de 3.424 especies de plantas vasculares registradas (se destacan el cedro, caraño, laurel, anime, gualanday, yarumo, caimo, guadua, entre otras). En cuanto a la fauna íctica, se estima que concurren más de mil especies de peces, destacándose los grandes bagres, la anguila eléctrica, las rayas de agua dulce y las pirañas. En anfibios se estima un total de 48 especies, seis de ellas endémicas: la rana arbórea hocicona de Kennedy, de Blair, de Villavicencio, entre otras. Los reptiles son abundantes, con un total de 107 especies (anaconda verde, caimán de concha, iguana verde, tortugas mata-mata, entre otras). En cuanto a la avifauna, se encuentran los garzones, coclíes, corocoras, gavilanes, halcones, búhos, entre otros. Entre los mamíferos destacan los chigüiros, el oso hormiguero gigante, el armadillo hocicudo de los llanos, la zorra comedora de cangrejos, el perro montés, el ocelote, el felis, el jaguar, la nutria gigante, el mono aullador rojo, alrededor de 54 especies de murciélagos, entre otros (Romero et al., 2004). Sin embargo, se llama la atención sobre la alta vulnerabilidad de esta diversidad biológica:

Pese a la gran riqueza biológica e hídrica de la región, muchos de las ecosistemas se han visto afectados por las presiones antrópicas originadas de manera acelerada entre mediados de los años setenta a noventa (...). La expansión de las zonas de cultivo, que se han triplicado en un lapso de diez años, se debe principalmente a la plantación de palma africana y frutales, con 579.000 y 77.000 nuevas hectáreas, respectivamente. Este fenómeno, asociado a actividades ilícitas de siembra de coca localizadas principalmente en las riberas de los grandes ríos como el Guaviare, la explotación petrolera de enclave a lo largo del piedemonte araucano y casanareño, el aumento de cultivos de arroz, la extracción de recursos naturales hacia el interior del país y el desarrollo de la infraestructura, ha impulsado el aumento de la población

7 El concepto de biodiversidad o diversidad biológica se refiere a la variedad en el interior del mundo viviente, y presenta diferentes grados de complejidad (variabilidad genética de poblaciones, multiplicidad de especies, diversidad de ecosistemas y paisajes). Estos niveles, interrelacionados entre sí espacial y funcionalmente, se estudian desde el nivel de genes, especies, comunidades, hasta los ecosistemas y paisajes (IAvH, 2000, en Romero et al., 2004). 
generando una presión cada vez mayor sobre los recursos naturales, principalmente en la zona de piedemonte y en las cuencas de los principales ríos, propiciando cambios significativos en la economía regional, la dinámica poblacional y, por supuesto, en la biodiversidad de la zona (Romero et al., 2004, pp. 16-17).

Este discurso, que se basa en la concepción de la región como una zona biodiversa y en riesgo, se hibridiza con significaciones que presentan la cuenca del Orinoco como una de las últimas "áreas silvestres" o "regiones vírgenes" del planeta (Rivas, Rodríguez \& Mittermeier, 2002). Esta visión se inscribe en el discurso mundial de la conservación de regiones megadiversas, y presenta la región como un área en la cual coinciden tanto una alta biodiversidad como amenazas de pérdida.

En la consideración de la Orinoquia — siguiendo a Germán Andrade (2009)_como un área especial desde una visión conservacionista, no siempre se reconoce la larga historia de ocupación y transformación de los ecosistemas, que se refleja en una población humana en algunos sectores más concentrada, pero dispersa y de baja densidad en la mayoría del territorio, aunque cubre toda la región. Tampoco se reconoce que gran parte de esa extensa "naturaleza" está representada por ecosistemas naturales manejados, esto es, sistemas ecológicos que, a pesar de sus cambios, mantienen su composición y estructura en un estado no muy diferente del original, tales como la ganadería criolla y la quema de las sabanas. La quema de las sabanas, uno de los sistemas tradicionales de vida en el llano, tiene como objetivo renovar pasturas y facilitar la caza. Evita la acumulación de biomasa en el suelo y libera nutrientes (Rodríguez, 2009). En promedio, entre 2000 y 2008 se quemaron tres millones de hectáreas durante la temporada seca, lo que equivale a 4 por ciento del total de las quemas de Sudamérica ( Tansley et al., 2008, citado en IAvH, 2009, en Rodríguez, 2009).

Este discurso de conservación que busca "alejar" las actividades antrópicas del territorio "natural", y que resalta los atributos naturales y biodiversos de la Orinoquia colombiana, constituye una cierta imagen de conservación romántica sobre el carácter "silvestre" de la zona, en el cual sus paisajes y sus habitantes nativos se ven estetizados y erotizados.

El paisaje tropical transformado en espectáculo y los mudos especímenes que lo habitan dispuestos para ser expuestos, para ser consumidos. En primer plano se evidencian las complejas conexiones que entrelazan los paisajes y los cuerpos exóticos. Ambos saturados de naturaleza y dispuestos abiertamente para ser transformados. No gratuitamente la literatura de viajes coloniales está llena de metáforas sexuales con las que se describe el encuentro y la conquista, como los paisajes tropicales voluptuosos y accesibles. Su consumo visual, tanto como su posesión y su uso a través de la intrusión, es un rasgo central a su definición social como naturales, inferiores y femeninos. Es un rasgo central de la ambigüedad de su naturaleza salvaje que representa una amenaza y a la vez una promesa. A su naturaleza infantil e inerme, por lo que nunca duda que deben estar bajo tutela y responsabilidad de la mirada civilizadora (Serje, 2005, p. 232).

Mediante el proceso de estetización, el sujeto se abstrae de su contexto particular para ser ubicado en el marco de una nueva significación, valorada según los 
cánones de la sensibilidad occidental. Así, la cultura material e inmaterial de estas regiones pasa a ser objeto: "el indio arqueologizado", preservado en nuevos contextos, como el del museo, la colección, la comparación tipológica. Pasa a constituirse en objeto de misterio, de sueños, de encuentros diversos y de perversas utopías. Deviene la región en ser mítico y en paraíso fantasmal (Serje, 2005).

\section{De espacio a lugar intercultural}

El discurso que configura la región orinocense como un lugar intercultural rivaliza con la visión de la cuenca del Orinoco como espacio vacío sin mayores obstáculos ambientales y culturales que vencer, que es la que sustenta el discurso dominante. En este discurso hegemónico, la región es primordialmente un espacio, convertido en objeto de análisis; es percibida física y empíricamente como forma y proceso plausible de ser medido y cartografiado. ${ }^{8}$ El supuesto que subyace en tal orientación es que es necesario romper con las tradiciones, arraigos, conocimientos y valores de las sociedades llamadas "ancestrales", esto debido a que tales particularidades son las que auspician la heteroglosia espacial, vale decir, los múltiples significados del territorio que residen en las vivencias y pensamientos de los pobladores de estos lugares.

A continuación se presentan dos correlatos que ilustran la tensión histórica que aún persiste, hoy actualizada, entre las percepciones que asumen la región como espacio homogéneo, y aquellas que validan la región como un lugar intercultural. Estos dos correlatos se pueden referir de la siguiente manera: de espacio de promisión a zona de fronteras; y de zona de frontera a interacción de culturas.

De espacio de promisión a zona de frontera. Quizá el discurso con más historia es el que construye la Orinoquia como un espacio de promisión. $\mathrm{Al}$ respecto, el relato de Joseph Gumilla describe cómo los europeos tratan de poseer El Dorado del Orinoco:

Diego Ordáz, que como dije, fue el primero que recejó y venció las corrientes del Orinoco, había vuelto de España con poderes del señor Emperador Carlos Quinto, para que sólo Ordáz, y no otro, corriese con el descubrimiento del Dorado, y de todo el Orinoco (...) pero sonó en Inglaterra el eco del Orinoco y del Dorado, y luego partió en su busca [sic] monsieur Ralego, y entró en dicho río con mano armada año de 1545 para ser testigo de sus pérdidas, y desgracias, y no más. El año siguiente de 1546 otro inglés, llamado Keymisco, envidiando los tesoros, que suponía en manos de Ralego, se armó, navegó, y se asomó a la Guyana: temió, y se retiró sin honra, y sin dinero (Gumilla, 1944, pp. 60-61).

Según el historiador colombiano Héctor Publio Pérez, desde el momento de la llamada conquista, los llanos orientales pasaron a ser una zona de frontera auspiciada por el sueño del Dorado:

8 Entre enero de 1850 y febrero de 1859 , el territorio de la Nueva Granada fue sometido, por primera vez, a estudio geográfico sistemático. Durante nueve años la Comisión Corográfica, dirigida por el geógrafo militar italiano Agustín Codazzi, visitó la mayor parte de las regiones del país, llevando registro de sus características geográficas y topográficas, así como de sus recursos naturales, sus industrias y sus condiciones sociales (Sánchez, 1999). 
Con la llegada del blanco europeo y su avanzada colonizadora, los llanos se convirtieron en una zona de frontera; abriendo trochas y caminos fueron penetrando en estas tierras sobre todo con el afán de buscar fortuna, de buscar el famoso Dorado o Xerirá (Pérez, 2003, p. 65).

En este contexto de lucha interétnica surgieron y se reprodujeron nociones y concepciones en torno a la naturaleza "salvaje", "primitiva" y "belicosa" de los indios, que justificó socialmente la "guerra justa contra estos": "Todo el mundo sabe que el indio es un indio. Que mata y roba el ganado de los colonos (...) no sabe hacer nada. Son salvajes” (El Tiempo, 1973, en Gómez, 2006, p. 17). Cazar indios ("Kuivar", "Guahibiar") fue una práctica común en los llanos, ejecutada por colonos y hacendados que poco a poco fueron estableciéndose en la región, disputándose y reduciéndoles a los indígenas sus espacios de hábitat tradicional y, por supuesto, restringiéndoles el acceso a los recursos de sus territorios (Gómez, 2006).

De zona de frontera a interacción de culturas. Siguiendo a Jane Rausch (2003), la frontera "colombiana" fue una línea en la que la colonización hispánica se encontró con la selva y la sabana, aunque en este caso estos ecosistemas no estaban aislados, vacíos, sino poblados y estructurados por comunidades indígenas. Así, la frontera se constituyó en una zona de interpenetración de dos sociedades hasta ese momento completamente distintas. Con el correr de los siglos, la dinámica de interacción entre culturas y gentes en estas zonas produjo identidades regionales.

En las últimas décadas, la localización de los grupos indígenas se ha modificado a causa de los cambios en los patrones de asentamiento, las dinámicas de migración y presión poblacional, el desplazamiento, y debido a la intervención de grupos armados fuera de la ley. La siembra de cultivos de uso ilícito y la delimitación de los resguardos donde muchos de los antiguos grupos nómadas se han establecido también han desempeñado un papel. Actualmente, la población amerindia de la baja llanura está organizada en pequeños núcleos pertenecientes a los pueblos Hitnu (Macaguán), Betoye, Kuiba (Wamone), Sikuani (Guahibo) y Sáliba, además de aquellos que se concentran en el resguardo de Caño Mochuelo. En los contrafuertes de la cordillera Oriental habitan los U'wa, mientras al sur del río Meta, en la alta llanura, los indígenas Sikuani y Piapoco se asientan en comunidades de horticultores y cazadores. En inmediaciones de los ríos Guaviare e Inírida se localizan los grupos Puinave, Piaroa y Kurripako (Sánchez, s/f).

9 Enrique Sánchez (2009) recuerda parte de la experiencia de violencia étnica que tuvieron que afrontar estos grupos en las últimas décadas del siglo anterior: "Los grupos Kuiva fueron grupos víctima de masacres en Arauca en los años sesenta. Para matarlos envenenaban la sal que consumían, ya que competían con el ganado por la sal; es el caso de la Hacienda de la Arenosa, de unos hacendados de origen español. Otro caso fue el que sucedió en La Rubiela en donde los asesinaron a garrote porque no valía la pena gastarse un tiro" (p. 7). En la masacre de La Rubiela, en donde fueron asesinadas diecisiete personas, dos indígenas sobrevivieron y por ellos se supo de la muerte de sus parientes. Cuando las autoridades de Colombia y Venezuela iniciaron la investigación, todos los procesados confesaron espontánea y naturalmente su participación en los hechos, con lujo de detalles, pero con la afirmación categórica de que "no sabían que matar indios fuera malo" (Gómez, 2006, p. 13). 
CUADRO 1 | Grupos indígenas, población y número de resguardos en departamentos articulados territorialmente a la cuenca del Orinoco colombiano

\begin{tabular}{|c|c|c|c|c|c|}
\hline DEPARTAMENTOS & GRUPOS INDÍGENAS & \multicolumn{2}{|c|}{ POBLACIÓN } & \multicolumn{2}{|c|}{ RESGUARDOS $^{A}$} \\
\hline Arauca & $\begin{array}{l}\text { Betoye, Chiricoa, Hitnu, Kuiba, } \\
\text { Piapoco, Sikuani, U'wa }\end{array}$ & 3.279 & $(2,2 \%)$ & 26 & $(3,7 \%)$ \\
\hline Boyacá & U'wa, Muisca & 5.859 & $(0,5 \%)$ & 1 & $(0,1 \%)$ \\
\hline Casanare & $\begin{array}{l}\text { Amorúa, Kuiba, Masiguare, } \\
\text { Sáliba, Sikuani, Tsiripu, Yaruros, } \\
\text { U'wa }\end{array}$ & 4.102 & $(1,5 \%)$ & 10 & $(1,4 \%)$ \\
\hline Cundinamarca & Muisca & 7.401 & $(0,3 \%)$ & & \\
\hline Meta & $\begin{array}{l}\text { Achagua, Guayabero, Nasa, } \\
\text { Piapoco, Sikuani }\end{array}$ & 8.988 & $(1,3 \%)$ & 20 & $(2,8 \%)$ \\
\hline Vichada & $\begin{array}{l}\text { Kurripako, Piapoco, Piaroa, } \\
\text { Puinave, Sáliba, Sikuani, Amorúa }\end{array}$ & $17.663^{\mathrm{b}}$ & $(44,3 \%)$ & 32 & $(4,5 \%)$ \\
\hline
\end{tabular}

fuente Elaboración propia, basada en el Censo de 2005, del Departamento Administrativo Nacional DE ESTADÍSTICAS (DANE) Y EN DANE, 2007.

NOTAS A EN LA ACTUALIDAD EXISTEN 710 RESGUARDOS TITULADOS UBICADOS EN 27 DEPARTAMENTOS Y EN 228 MUNICIPIOS DEL PAÍS, QUE OCUPAN UNA EXTENSIÓN DE APROXIMADAMENTE 34 MILLONES DE HECTÁREAS, EL 29,8 POR CIENTO DEL TERRITORIO NACIONAL. ESTAS CIFRAS EVIDENCIAN UN INCREMENTO SIGNIFICATIVO DEL 127 POR CIENA CENS DE 1993 (DANE 2007) B SEGÚ

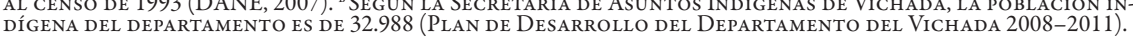

Uno de los grupos indígenas más representativos de la región es en la actualidad el de los Guahibo, que se llaman a sí mismos Guayapropiwiwui, gente de la sabana, y que organizan las actividades de subsistencia en los conucos de acuerdo con los regímenes de lluvia y sequía (Romero et al., 2005). Sin embargo, esto parece estar cambiando en algunas zonas. Sánchez (2009) presenta el caso en que el trabajo tradicional se hibridiza, muta hacia otro tipo de práctica, la que es introducida por nuevos actores de la región: las petroleras. Según ese autor, los grupos indígenas de la región se encuentran hoy en peligro de extinción.

Ahora la población indígena está muy diezmada, pobre y con una participación fracturada. Hay un fenómeno que merece capítulo aparte, es el tema de los indígenas de Orocué; los Sáliba, estos son de familia Arawak. Estos Sáliba, a diferencia de los otros, eran agricultores, sedentarios, de conucos estables, y fueron los que más rápidamente se incorporaron; fue a los primeros que les llega el petróleo. Ese impacto del petróleo fue muy grande, a pesar de que la compañía que llegó ahí, fue una compañía francesa. El problema de las petroleras es que son muy asistencialistas y no contemplan las estructuras culturales y las civilizaciones, entonces siempre generaron problemas muy grandes de deterioro de esta sociedad (Sánchez, 2009, p. 8).

La Oficina de Asuntos Indígenas de Vichada coincide con Sánchez al afirmar que algunas comunidades indígenas de la región presentan altos grados de vulnerabilidad y riesgo de extinción; es el caso de la etnia Amoruas, que está ubicada en 
Puerto Carreño (Vichada). A inicios del presente siglo, este grupo contaba con una población de 1.200 indígenas; hoy su población es de 300 personas. Tal situación se describe en el actual Plan de Desarrollo de Vichada de la siguiente manera:

En los últimos años, los territorios indígenas del país han venido siendo afectados por la violencia generalizada; ante esta situación, la mayoría de organizaciones indígenas y sus comunidades han tomado la decisión de resistir en los territorios, pero ante la profundización del conflicto, en los últimos cuatro años se viene produciendo éxodo y desplazamiento, en tanto que las comunidades que no se desplazan sufren el problema de bloqueo, el debilitamiento organizativo, la descomposición cultural y la profundización de la pobreza. (...) [En el caso del pueblo Amorúa], la colonización y la explotación de grandes hatos ganaderos y actualmente la instalación de megaproyectos agroindustriales los ha afectado significativamente, porque los ha aislado, pues a pesar de su carácter seminómada, habían iniciado un proceso de sedentarización (Gobernación del Vichada, 2008, pp. 41-42).

Corroborando lo anterior, la Sentencia de la Corte Constitucional de Colombia, Auto 004, de 2009, declara que la situación de los individuos, familias y comunidades indígenas desplazados forzosamente es grave por una multiplicidad de factores distintos: i) problemas de alimentación: ii) ruptura de pautas culturales y falta de acceso a los alimentos que tradicionalmente consumen, lo que desemboca en situaciones de hambre; iii) ayuda humanitaria de emergencia usualmente inadecuada y que no responde a las especificidades culturales de los pueblos desplazados; iv) bloqueo del acceso a las formas tradicionales de medicina; $v$ ) individuos y comunidades indígenas en situación de desplazamiento por falta de capacidades y competencias culturales para afrontar la vida urbana, en condiciones extremas de miseria y desprotección y expuestos a riesgos de todo tipo: ser víctimas de violencia sexual, caer en redes de comercios ilícitos, verse obligados a la mendicidad, explotación y discriminación (por intolerancia, racismo e ignorancia de los pobladores en los lugares de recepción); el conflicto armado está presente en los lugares de llegada, o los persigue hasta allí, generando nuevos riesgos para su integridad individual y colectiva, y la inseguridad en los lugares de recepción a su vez fuerza a retornos involuntarios y sin seguridad, o a re-desplazamientos (Corte Constitucional de Colombia, 2009).

La siguiente es la caracterización de las comunidades indígenas que hizo la Dirección de Etnias, al priorizarlas en el Plan Integral de Apoyo a Comunidades Indígenas en Alto Grado de Vulnerabilidad y Riesgo de Desaparición, aprobado el 13 de junio de 2006:

a) Casanare: Etnias Wipiwi, Tshiripo, Yamaleros, Yaruros, Amorúa, Maiben. Comunidades de Hato Mochuelo, Hato Corozal - municipio de Paz de Ariporo; 845 personas. Presentan altos índices de morbimortalidad, disminución progresiva de la población; ocho pueblos indígenas conviven en un solo resguardo, lo que genera conflictos por territorio, acceso alimentario y servicios. Etnia Sáliba: ocho comunidades en Orocué, 520 personas: riesgo de desaparición por disminución progresiva de la población y "seminomadismo sin alternativas integrales de sedentarización". 
b) Meta: Etnias Sikuani y Piapoco en Puerto Gaitán - riesgo de desplazamiento; cinco comunidades: El Tigre. Etnia Piapoco en Mapiripán: confinamiento, desplazamiento: Caño Ovejas. Etnia Achagua en Puerto Gaitán y Mapiripán - riesgo de desaparición, desplazamiento, confinamiento: Caño Ovejas. Etnia Guayabero en La Macarena y Puerto Concordia - cinco comunidades: Caño Ceiba, Caño Mina; riesgo de desplazamiento, confinamiento. Todos los grupos del Meta: disminución progresiva de la población, altos índices de morbimortalidad, afectación de la integridad étnica por conflicto armado, inexistencia de presencia institucional, no tienen condiciones para la sedentarización.

c) Arauca: Etnias Sikuani, Macaguán, Kuiva, Betoye, Hitnu, Chiricoa; 18 comunidades: Río Viejo, Playeros-Cájaros, Bayoneros, El Vigía, Cravo, Cusay-La Colorada, Cibariza, Los Iguanitos, Alto Cabalalia, La Cabaña, San José del Cangrejo, Graneros, Julieros y Velasqueros, Macarieros, Barreros, Puyeros, Roqueros, El Dorado, Caño Claro, Cuiloto, La Esperanza; 1.906 personas. Riesgo de desaparición, desplazados, confinamiento: progresiva disminución de la población, cultivos de uso ilícito en sus territorios, débil presencia institucional, territorios minados, disputas territoriales, conflictos con colonos, megaproyectos (hidrocarburos).

Hoy los grupos indígenas esperan ser tratados dignamente, que se les respeten sus costumbres, tradiciones y formas de vida. Pero mientras ello ocurre, el futuro de la Orinoquia es incierto para estos pobladores llamados "originarios", condenados no a vivir, sino a sobrevivir en una región de la cual en algún tiempo fueron "dueños" y donde con el pasar del tiempo, y sin darse cuenta, se convirtieron en mendigos y extraños en su propia tierra (Galindo, 2009).

Entre los actores sociales con tradición en la región están también los llamados llaneros criollos o, como se autodenominan, llaneros originarios, provenientes del mestizaje entre los primeros colonizadores y los indígenas nativos. Su estructura económica, social y cultural está representada por el trabajo en el hato. Este, que constituye la forma de organización productiva, social y cultural del llano, es tributario de las reducciones, pacificaciones y poblados a los que fueron sometidos los pueblos indígenas en momentos de la primera gran colonización. Se desarrolla por medio de fundos y requiere del trabajo en el campo con el ganado, la vaquería. El hato, como estructura de producción y modelo de vida, ha generado formas particulares de organización social a partir de las cuales se establecieron jerarquías y oficios, que hasta la actualidad han organizado gran parte de la vida de los pobladores rurales. En los hatos tradicionales se hacen dos trabajos de llano al año - a la llegada y al final de las lluvias (Sánchez, s/f) - y con ello se ha desarrollado un sistema de conocimiento que integra relaciones económicas y culturales con el funcionamiento cambiante de los ecosistemas de la región. Al respecto, Romero y Romero (2005) comentan:

La ganadería tradicional tiene como característica central, su proceso de adaptación histórico a nichos ecológicos de la sabana, matas de monte y sabanas, de tal forma 
que el ganado permanece en la sabana en invierno cuando ya ha crecido el pasto y en las matas de monte en verano (p. 18).

Más recientemente, a raíz de la violencia vivida en el país a mediados del siglo pasado y como solución a conflictos de tenencia de tierra en la zona andina, muchos campesinos del interior se asentaron en el piedemonte de la cordillera Oriental. A estos migrantes de mitad de siglo se les conoce como nuevos llaneros. En las últimas décadas, a raíz de la "fiebre del petróleo" o de las "fiebres verdes" y los desplazamientos forzados, muchos campesinos de distintos lugares del país han migrado con sus familias a la región, ocupando algunas zonas de piedemonte y de sabana, y con ellos se empieza a gestar una nueva cultura, la de los llaneros nuevos.

En las vegas de los ríos emerge otro actor social tradicional de la región, el veguero. En esas angostas franjas en las orillas inundables conviven el veguero estacional y el permanente, nativos cuya principal actividad es la pesca y la agricultura tradicional. En las partes altas, mejor drenadas, plantan cultivos permanentes (yuca, plátano); y en las vegas bajas, de mayor fertilidad, siembran cultivos de ciclo corto (maíz, tubérculos) (Forero et al., 1997). Según Silva (2009), presidente de la Asociación de Algodoneros y Agricultores del Vichada $\left(\right.$ Asalvi $\left.{ }^{10}\right)$ :

Las vegas se caracterizan por estar en zonas de terrenos baldíos de propiedad de la nación, ubicadas sobre las márgenes de los ríos Meta y Orinoco, en las cuales los vegueros establecen cultivos de pan-coger como patilla, melón, plátano, yuca, fríjol, ahuyama, entre otros que surten el mercado local y departamental (p. 6).

Los cultivos en las vegas, las pequeñas huertas de los fundos, la pequeña ganadería en sabanas comunales y los conucos de las comunidades indígenas y campesinas, concentran formas de producción tradicional agrícola de la altillanura y la llanura húmeda. Estas formas de economía tradicional implican conocimientos y comprensiones sobre el medio natural que pautan, de manera sostenible, la vida social y cultural.

Veamos el relato que construyen Romero y Romero (2005) para ilustrar esta imagen de la región como lugar intercultural:

Adoptando la noción del lugar donde se mezclan las culturas, es posible que la Orinoquia colombiana sea la región en donde se forme y desarrolle el nuevo tipo de hombre colombiano, no con una cultura e ideología andinas, sino como elemento de una sociedad cuyo hábitat es la sabana y la selva y en donde a partir de la población del Tolima, Valle, Huila, Boyacá y la población nativa, tenga lugar una amalgama étnica y cultural, o sea un hombre nuevo, una sociedad nueva (p. 22).

Este discurso que construye la Orinoquia como lugar intercultural evidencia cierta sedimentación de conflictos y vivencias, que se expresan en formas distintas de apropiar el territorio, esto es, de convertir el espacio social en lugar. Las imágenes que aparecen como correlatos de este discurso no hegemónico albergan rasgos

10 Asalvi está conformado por un grupo de pequeños agricultores que, considerando sus necesidades económicas, decidió agrupar familias de agricultores por tradición en una asociación sin ánimo de lucro. Estas familias han venido cultivando en las vegas de los ríos Meta y Orinoco por espacio de más de cuarenta años. En la actualidad, la asociación cuenta con 168 afiliados; este año hay 100 familias de estrato 1 que cultivan algodón y maíz (Silva, 2009). 
de una cultura ya no agenciada sobre la "pureza de sangre", sino construida a partir de la mezcla, de la exaltación del mestizo. ${ }^{11}$ Tal auspicio contiene el riesgo de la negación cultural-ontológica inscrita en la invitación forzosa a evolucionar en una tercera categoría: ni indios, ni blancos, sino mestizos (De la Cadena, 2005). Siguiendo, de manera libre, a la autora, mantener una heteroglosia de los mestizos en la Orinoquia colombiana lleva a reivindicar la "doble conciencia", esto es, el rechazo a la simple semejanza y la activa apropiación de los dispositivos que conectan, por ejemplo, la indigenidad con la no indigenidad, que vuelve su separación inútil o un mero ejercicio de retórica dominante y de la creación de políticas.

En igual sentido, Santos (2010) plantea que en el contexto de América Latina el mestizaje es producto del colonialismo y de las políticas indigenistas. Aun cuando se reconoció la identidad cultural indígena, la ideología del progreso fue siempre identificada con aculturación eurocéntrica y con "blanqueamiento". La hibridación empírica (mezcla de sangres) fue casi siempre negada en cuanto hibridación conceptual, debido la identificación tendencial del mestizo-blanco con los blancos. En estos tiempos, la lucha indígena por la plurinacionalidad no deja de ser hostil a la idea de mestizaje. "Lo que yo pienso en cambio es que este estado de transición debe volverse históricamente, no en función del mestizo como amalgama, sino del mestizo, pero en su expresión social más oprimida, que es la del mestizo-indio" (Salazar, 2008, en Santos, 2010, p. 123).

\section{A modo de apertura}

Hasta aquí se han descrito los principales rasgos de tres tipos de discursos que luchan en la actualidad por constituir el presente y futuro de la Orinoquia colombiana: i) zona con territorios inmensos y vacíos (visión hegemónica); ii) área para la conservación; y iii) lugar intercultural. Se ha privilegiado una tesis central, y es que estos discursos contemporáneos sobre y desde la Orinoquia colombiana contienen herencias moderno-coloniales.

En el presente, la región orinocense se encuentra en el centro del debate gubernamental, privado, comunitario y académico. Son dos los interrogantes que guían tal discusión nacional: ¿Cómo orientar el proceso de transformación económica, social, cultural y ecológica sin precedentes que vive la región? ¿Qué tipo de acuerdos sociales podrían asegurar que las transformaciones actuales y venideras no pongan en riesgo su valor ecosistémico y cultural? Son preguntas que, sin lugar a dudas, implican procesos de de-construcción de los arraigos de la colonialidad y procesos de re-construcción de las vivencias, conocimientos y subjetividades negadas por estas condiciones de dominio, esto en aras de constituir potencias colectivas anidadas en la pluralidad epistémica y cultural (Santos, 2010).

Uno de los principales retos es el de agenciar dispositivos de relación plural que permitan transformar las condiciones de dominio que fomentan la injusticia,

11 Algunos significados del término "mestizo" se han convertido en obvios, invisibilizando otras formas de comprensión. La versión empírica - la observación científica de la mezcla de los cuerpos, cultura, raza; mezcla de dos (a veces más) identidades raciales previamente puras - contiene un supuesto implícito: la latente pureza (De la Cadena, 2005). 
la segregación y la destrucción de ecosistemas. Dispositivos donde los múltiples discursos tengan "cabida" real desde la diferencia; en especial, aquellos construidos desde modelos de conocimiento que aparecen, a la luz del modelo epistémico moderno-hegemónico, marginados o invisibilizados, por habérseles considerado "míticos", "orgánicos", "supersticiosos" y "pre-racionales" (Castro-Gómez, 2007). El privilegio de formas de conocimiento excluyente y normativo no solo es un obstáculo epistémico para la pluralidad de lo político, sino que, a su vez, legitima la instauración de "consensos" sobre lo social con grados crecientes de injusticia, desigualdad e indiferencia (Wallerstein, 2001).

Quizá una pista para hacer realidad estos dispositivos de relación plural sea reconocer de manera franca a los actores locales tradicionales, que en desiguales condiciones de poder y de saber luchan por construir la Orinoquia colombiana. Los sistemas productivos tradicionales ejemplifican formas sustentables de concebir la economía de los pueblos; los ciclos de las aguas son muy bien comprendidos y manejados por los vegueros productores del Orinoco; las relaciones entre fauna, pesca, morichales, matas de monte y pastizales de sabana son entendidas por el llanero criollo; y la organización, el clima y la rotación de cultivos, por los indígenas. Teniendo presente que no se trata ni de idealizar ni de esencializar los conocimientos tradicionales, lo que sí se busca es restituir subjetividades, prácticas y saberes enmarcados dentro de procesos de generación de vida social en condiciones de justicia y de sostenibilidad tanto ecosistémica como generacional. En este proceso, el Estado en sus diferentes niveles ha de asumir su responsabilidad constitucional, la de ser el garante fundamental y el "guardián" del bien común, para que sea este un principio rector del proceso - no un principio de papel, sino un principio real一, que coadyuve a forjar una Orinoquia justa y sustentable en el tiempo.

$\mathrm{Y}$ es que forjar la Orinoquia desde las diferentes formas de vida, conocimientos y dominios que hacen presencia allí, es reconocer esta región como un lugar intercultural, donde lo cultural se convierte en política. La cultura es política, porque los significados son elementos constitutivos de procesos que, implícita o explícitamente, buscan dar nuevas definiciones de poder social. Es decir, cuando los actores sociales despliegan conceptos alternativos de naturaleza, territorio, raza, economía, desarrollo, democracia o ciudadanía, los cuales desestabilizan significados culturales dominantes, ponen en marcha una política cultural (Escobar, 2001).

Por último, cuestionar y transformar las condiciones de colonialidad presentes en la región es hoy un proceso central para agenciar desde la igualdad y la diferencia la cuenca del Orinoco. Quizá una forma para ir "desactivando" tales dominios tiene que ver con hacer cotidianas, en la vida de las gentes interesadas en la región, relaciones cada vez más marcadas por la pluralidad epistémica y la justicia cognitiva. Justicia cognitiva, que lleve a reensamblar lo social desde lo solidario y desde el bien colectivo. Procesos que pueden estar hoy resonando en las experiencias de vida de algunos de los pobladores de la región; en las palabras de los abuelos narradores de historia tradicional que se reúnen en el Casanare y en el Meta; en los 
consejos de los Capitanes y Taitas de los resguardos del Vichada; en la cotidianidad de los vegueros del caño Chorrosco, así como en la vivencia y expectativa de vida de otros, de otros muchos más, que con sus prácticas están día a día contribuyendo a hacer realidad ese sueño que comparten muchos: el de ayudar a construir colectivamente una región que sea sustentable, no solo ambiental y económicamente, sino también social y culturalmente. OEURE

\section{Referencias bibliográficas}

Agencia Nacional de Hidrocarburos (ANH), Colombia (2009). Documento explicativo del proyecto "Desarrollo de crudos pesados en la cuenca de los Llanos Orientales-Área Oriental, Santa Rosalía, Vichada, Colombia" [Documento interno de trabajo, sin publicar].

Andrade, G. (2009). La mejor Orinoquia que podemos construir [Documento interno]. Bogotá: Universidad de los Andes.

Bury, J. (1971). La idea del progreso. Madrid: Alianza Editorial.

Castro-Gómez, S. (2005). La hybris del punto cero. Bogotá: Editorial Pontificia Universidad Javeriana.

Castro-Gómez, S. (2007). Decolonizar la universidad. La hybris del punto cero y el diálogo de saberes. En S. Castro-Gómez \& R. Grosfoguel (Eds.), El giro decolonial: Reflexiones para una diversidad epistémica más allá del capitalismo global. Bogotá: Pontificia Universidad Javeriana/Instituto de Estudios Sociales Contemporáneos (Iesco), Universidad Central/Siglo del Hombre Editores. En http://www.lapetus.uchile.cl/lapetus/archivos/1307460584Castro GomezSantiago-ElGiroDecolonial.pdf

Comisión Corográfica (1959). Jeografía física i politica de las provincias de la Nueva Granada. Bogotá: Publicaciones del Banco de la República.

Comte, A. (1984). Curso de filosofía positiva (Lecciones 1 y 2); Discurso sobre el espiritu positivo. Barcelona: Orbis.

Corte Constitucional de Colombia (2009). Auto 004-09, Bogotá: Autor.

De la Cadena, M. (2005). ¿Son los mestizos híbridos? Las políticas conceptuales de las identidades andinas. Universitas Humanistica, 61, 51-85 (Bogotá: Pontificia Universidad Javeriana).

Departamento Administrativo Nacional de Estadísticas (DANE). (2007). Colombia, una nación multicultural. Su diversidad étnica. Bogotá: DANE, Dirección de Censos y Demografía.

Departamento Nacional de Planeación (DNP). (2007). Plan Nacional de Desarrollo 2006-2010. Estado comunitario: desarrollo para todos. Tomo II. Bogotá: Imprenta Nacional de Colombia.

Dussel, E. (1995). The invention of the Americas. Eclipse of "the Other" and the myth of modernity. Nueva York: Continuum Publishing.

Dussel, E. (2007). Politica de la liberación. Historia mundial y crítica. Madrid: Editorial Trotta.

El Tiempo (1973). La alternativa del Cuiva: matar como tigre, morir como perro. El Tiempo, Lecturas Dominicales, 5 de agosto, 1-2.

Escobar, A. (1998). La invención del tercer mundo: construcción y deconstrucción del desarrollo. Bogotá: Norma.

Escobar, A. (2000). El lugar de la naturaleza y la naturaleza del lugar: ¿globalización o postdesarrollo? 
En E. Lander (Comp.), La colonialidad del saber, eurocentrismo y ciencias sociales. Buenos Aires: Consejo Latinoamericano de Ciencias Sociales (Clacso)/Organización de las Naciones Unidas para la Educación, la Ciencia y la Cultura (Unesco).

Escobar, A. (2003). Mundos y conocimientos de otro modo. Tabla Rasa, 1 (Bogotá: Universidad Colegio Mayor de Cundinamarca).

Escobar, A., Álvarez, S. \& Dagnino, E. (Comp). (2001). Política cultural y cultura política. Bogotá: Instituto Colombiano de Antropología e Historia/Taurus.

Forero, J., Cifuente, E., Murgueitio, E., Durana, C., Barriga, M., Gómez, M. H. (...), Molina, E. (1997). Interacciones ecosistémicas y socioeconómicas de los sistemas de producción en la Orinoquia. En J. Forero \& C. Durana, Sabanas, vegas y palmares. Reflexiones sobre el uso del agua en la Orinoquia (pp. 261-298). Bogotá: Universidad Javeriana, Instituto Mayor Campesino.

Foucault, M. (2002). El orden del discurso. Barcelona: Fábula Tusquets Editores.

Galindo, Y. (2009). El futuro incierto de la Orinoquia. Ponencia presentada en el Foro La mejor Orinoquia que podemos construir, organizado por la Corporación Autónoma Regional de la Orinoquia (Corporinoquia), la Universidad de los Andes, la Friedrich Ebert Stiftung en Colombia (Fescol), el Foro Nacional Ambiental, la Gobernación de Vichada y la Procuraduría Delegada para Asuntos Ambientales y Agrarios; y realizado en Puerto Carreño, el 27 de noviembre de 2009.

Giddens, A. (1995). La constitución de la sociedad: bases para la teoría de la estructuración. Buenos Aires: Amorrortu Editores.

Giovanelli, F. (2009). Entrevista al Grupo Empresarial Manuelita, en el marco del proyecto "La mejor Orinoquia que podemos construir". Bogotá: Universidad de los Andes.

Gobernación de Vichada (2008). Plan de Desarrollo del Departamento de Vichada 2008-2011, Vichada el verdadero cambio... marca la diferencia. Puerto Carreño, Colombia: Gobernación del Vichada.

Gómez, J. (2006). Cuiviadas y Guajibiadas. El avance de la colonización ganadera y la guerra de exterminio contra los grupos indígenas cazadores-recolectores de los Llanos Orientales - Siglos XIX y XX. Caribabare. Revista del Centro de Historia de Casanare, 16(16), 11-30 (Casanare: Centro de Historia del Casanare).

Gumilla, J. (1944). El Orinoco ilustrado. Historia natural, civil y geográfica de este gran río. Bogotá: Editorial ABC.

Instituto de Investigación de Recursos Biológicos Alexander von Humboldt (IAvH). (2009). Informe sobre el estado de la biodiversidad en Colombia 2007-2008. Piedemonte orinocense, sabanas y bosques asociados al norte del río Guaviare. Bogotá: Autor.

Lander, E. (2000). Ciencias sociales: saberes coloniales y eurocéntrico. En E. Lander (Coord.), La colonialidad del saber: eurocentrismo y ciencias sociales. Perspectivas latinoamericanas. Buenos Aires: Consejo Latinoamericano de Ciencias Sociales (Clacso).

López Montaño, C. (2008). Carimagua, un modelo desplazador. El Tiempo (Bogotá), sección Nación, 18 de julio de 2008.

Maldonado-Torres, N. (2007). Sobre la colonialidad del ser: contribuciones al desarrollo de un concepto. En S. Castro-Gómez \& R. Grosfoguel (Eds.), El giro decolonial: Reflexiones para una diversidad epistémica más allá del capitalismo global. Bogotá: Pontificia Universidad Javeria- 
na/Instituto de Estudios Sociales Contemporáneos (Iesco), Universidad Central/Siglo del Hombre Editores. En http://www.lapetus.uchile.cl/lapetus/archivos/1307460584Castro GomezSantiago-ElGiroDecolonial.pdf

Mignolo, W. (2003). Os esplendores e as misérias da 'ciência': colonialidade, geopolítica do conhecimento e pluri-versalidade epistémica. En B. de Souza Santos (Ed.), Conhecimiento prudente para uma vida decente: um discurso sobre as 'ciências' revistado. Lisboa: Edições Afrontamento.

Pérez, H. (2003). Caminos reales de Casanare. Yopal: Gobernación del Casanare.

Quijano, A. (2001). Colonialidad del poder. Cultura y conocimiento en América Latina. En W. Mignolo (Comp.), Capitalismo y geopolitica del conocimiento. Buenos Aires: Ediciones del Signo/Duke University.

Rausch, J. (2003). La mirada desde la periferia: desarrollos en la historia de la frontera colombiana, desde 1970 hasta el presente. Fronteras de la Historia, 8, 251-260 (Bogotá: Ministerio de Cultura). En http://redalyc.uaemex.mx/pdf/833/83308009.pdf

Rivas, J., Rodríguez, J. V. \& Mittermeier, C. G. (2002. Los llanos. En P. Robles Gil (Ed.), Aéreas silvestres: Las últimas regiones vírgenes del mundo (pp. 264-273). México: Cemex, Conservación Internacional.

Rodríguez, M. (Dir.). (2009). La mejor Orinoquia que podemos construir. Elementos para la sostenibilidad ambiental del desarrollo. Bogotá: Corporación Autónoma Regional de la Orinoquia (Corporinoquia)/Universidad de los Andes, Facultad de Administración/Foro Nacional Ambiental/Friedrich Ebert Stiftung en Colombia (Fescol). En http://library.fes.de/pdffiles/bueros/kolumbien/07217.pdf

Romero, M. E. \& Romero, C. (2005). Desde el Orinoco hacia el siglo XXI: El hombre, la fauna y su medio. Bogotá: Fondo FEN (Financiera Energética Nacional).

Romero, M., Galindo, G., Otero, J., Armenteras, D. (2004). Ecosistemas de la cuenca del Orinoco colombiano. Bogotá: Instituto de Investigación de Recursos Biológicos Alexander von Humboldt.

Rostow, W. W. (1960). The stages of economic growth. Cambridge, MA: Cambridge University Press.

Salazar, C. (2008). Presentación. En B. de Souza Santos, Conocer desde el Sur. La Paz: Clacso-CidesPlural.

Sánchez, E. (2009). Entrevista realizada en el marco del proyecto "La mejor Orinoquia que podemos construir". Bogotá: Universidad de los Andes.

Sánchez, L. F. (s/f). Caracterización de los grupos humanos rurales de la cuenca Hidrográfica del Orinoco en Colombia, Diagnóstico del estado actual del conocer, conservar y utilizar, Plan de Acción Regional para la Orinoquia. Bogotá: Instituto de Investigación de Recursos Biológicos Alexander von Humboldt.

Santos, B. de Souza (2010). Refundación del Estado en América Latina. Bogotá: Siglo del Hombre Editores/Universidad de los Andes/Siglo XXI Editores.

Serje, M. (2005). El revés de la nación. Territorios salvajes, fronteras y tierras de nadie. Bogotá: Universidad de los Andes (Uniandes), Centro de Estudios Socioculturales e Internacionales (CESO).

Silva, A. (2009). Asociación de Algodoneros y Agricultores del Vichada (Asalvi). Ponencia presentada en el Foro La mejor Orinoquia que podemos construir, organizado por la Corporación Autónoma Regional de la Orinoquia (Corporinoquia), la Universidad de los Andes, la Frie- 
drich Ebert Stiftung en Colombia (Fescol), el Foro Nacional Ambiental, la Gobernación de Vichada y la Procuraduría Delegada para Asuntos Ambientales y Agrarios; y realizado en Puerto Carreño, el 27 de noviembre de 2009.

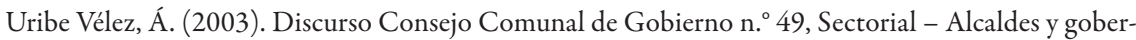
nadores salientes y entrantes de la Orinoquia. Bogotá. En http://www.presidencia.gov.co/ prensa_new/discursos/discursos2003/diciembre/cc_bogota.htm

Van Dijk, T. (2000). El discurso como estructura y proceso. Barcelona: Editorial Gedisa.

Viloria de la Hoz, J. (2009). Geografía económica de la Orinoquia. Serie Documentos de Trabajo Sobre Economía Regional, n. ${ }^{\circ}$ 133. Cartagena: Banco de la República, Centro de Estudios Económicos Regionales (CEER). En http://www.banrep.gov.co/documentos/publicaciones/ regional/documentos/DTSER-113.pdf

Wallerstein, I. (1984). El moderno sistema mundial. México: Siglo XXI.

Wallerstein, I. (2001). El eurocentrismo y sus avatares: los dilemas de la ciencia social. En W. Mignolo (Ed.), Capitalismo y geopolitica del conocimiento. El eurocentrismo y la filosofía de la liberación en el debate intelectual contemporáneo. Buenos Aires: Ediciones del Signo. 